\title{
LA EMPRESA Y EL ABANDONO DEL SOCIO EN TIEMPOS DE CRISIS...
}

Cristina Molina Aguilar

Investigadora de la Universidad de Jaén

Correo Electrónico: mcristina.molina@juntadeandalucia.es RESUMEN: La crisis económico financiera que ha atravesado España y la eurozona en general ha impactado con tal fuerza en el tejido empresarial que ha provocado en él efectos devastadores. Dichos quebrantos también se han manifestado en los desencuentros permanentes y las difíciles relaciones internas entre los accionistas que han visto en ocasiones, ante la conculcación de sus derechos, en el abandono de la compañía una posible solución para recuperar su inversión. En el derecho español con la promulgación del Texto Refundido de la Ley de Sociedades de Capital se recogen determinados casos aunque éstos son muy limitados y los socios que ven perjudicados sus intereses solamente pueden acudir a cláusulas estatutarias de separación que, en la mayor parte de los supuestos, no suelen ser introducidas ni previstas en los estatutos sociales.

Palabras Clave: Crisis; Empresa; Conflictos societarios; Derecho de salida de socio; Socio minoritario.

ABSTRACT: The financial economic crisis that has passed through Spain and the euro zone in general has impacted the business fabric that has caused devastating effects on it with such force. These losses have been expressed in the permanent misunderstandings and difficult internal relationships among the shareholders who have seen sometimes, against the violation of their rights, the abandonment of the company a possible solution to recover your investment. Spanish law with the promulgation of the text revised of the law societies of Capital includes certain cases but these are very limited and partners which adversely affected their interests only can go to statutory provisions of separation that, in most of the cases, tend not to be introduced nor provided for in the bylaws. .

Keywords: Crisis; Company; Corporate disputes; Right of exit of partner; Minority partner; 


\section{INTRODUCCIÓN}

El actual contexto de crisis económica y financiera que atravesamos afecta por igual a personas físicas, empresas, instituciones públicas y hasta al propio legislador a la hora de tomar decisiones que reduzcan el impacto del desequilibrio sobre la ciudadanía. Dichas vicisitudes, están teniendo numerosas repercusiones en los sistemas productivos de muchos países y en las compañías que sufren sus consecuencias demoledoras, siendo éstas duramente castigadas en el devenir de su actividad económica, lo cual conlleva consecuencias jurídicas para los agentes implicados en el momento en el que hay que enfrentarse a dificultades de negocio, de las que pueden sobrevenir la liquidación de la empresa ${ }^{1}$.

Con este panorama, si tradicionalmente el conflicto entre socios ha sido uno de los mayores y más desagradables problemas con los que venía enfrentándose el tejido empresarial debido a sus diferentes visiones internas sobre el modo de gestionar las empresas, hoy en día, no es de extrañar que los desencuentros se produzcan en mayor medida. Por ello, la institución jurídica del derecho de salida, representa una figura esencial dentro del marco protector de los intereses individuales del socio, aunque nuestro Ordenamiento Jurídico no aporte soluciones claras ni ofrezca una auténtica "puerta de salida" al socio minoritario, haciendo oídos sordos a un problema mucho más frecuente de lo que sería deseable, siendo los tribunales a día de hoy los únicos que están construyendo doctrina jurisprudencial, de difícil aplicación por estar basada en la teoría del abuso del derecho y en la causa de separación por concurrir justa causa ${ }^{2}$.

Es así que actualmente el instituto jurídico del derecho de separación del socio se regula en el Texto Refundido de la Ley de Sociedades de Capital a través del RDL 1/2010 de 2 de julio (en adelante TRLSC), pero a pesar de ser ésta figura una de las cuestiones

\footnotetext{
1 Entre dichas visicitudes se encuentra la dificultad de financiación de las empresas, esencial preocupación de las autoridades económicas de nuestro país, de Europa y de los principales organismos internacionales.

${ }^{2}$ Ibídem, el artículo 7 del Código Civil prohíbe el abuso del derecho o el ejercicio antisocial del mismo y la Jurisprudencia existente en la materia (entre otras, las Sentencias de 26/05/2005, 05/10/2011 y 07/12/2011 del Tribunal Supremo, o sentencias de audiencias provinciales como la de Álava de 19/10/2010, de Toledo de 14/01/2013 o de Gerona de 21/03/2013) vienen a defender la posición del accionista o socio minoritario ante los abusos de la mayoría.
} 
más delicadas e importantes para evitar que el minoritario quede atrapado en la sociedad esta institución jurídica está aún indefinida y es imprecisa su regulación -tanto por el contenido como por los fundamentos- ${ }^{3}$.

Por ello y con el escenario de reestructuración de la empresa en crisis en el que nos encontramos, el objeto de este trabajo es analizar cuál es el auténtico fundamento de esta figura jurídica, por lo que representa para el inversor minoritario en las sociedades de capital, a la vez que reflexionar sobre las razones que haya podido tener el legislador para efectuar varias modificaciones al TRLSC y darle a éste instrumento de defensa una tendencia fortalecedora -ampliando los supuestos legales e incorporando un nuevo Derecho al Dividendo-, a pesar de la poca idoneidad del momento económico en que lo lleva a cabo, siendo ésta normativa un producto jurídico con "fecha de caducidad" al tratarse de una legislación excepcional, casi de emergencia, con voluntad de provisionalidad y, por tanto, como una solución transitoria ${ }^{4}$.

\section{LA VIABILIDAD DE LA EMPRESA Y LA SALIDA VOLUNTARIA DEL SOCIO: ¿INTERESES ENFRENTADOS?}

Entre las manifestaciones más relevantes de la tutela del socio se encuentra el reconocimiento del derecho a romper su vinculación con la sociedad y obtener la liquidación y abono del importe de la cuota de su participación en el patrimonio de la compañía de la que se ha separado. El derecho de separación, aparece como una solución equitativa, transaccional o de compromiso para la CONCILIACIÓN DE INTERESES contrapuestos. Así, por un lado, el interés de la sociedad de proceder a la

\footnotetext{
${ }^{3}$ Desde la adopción del TRLSC, la regulación del derecho de separación ha sido objeto de varias modificaciones a través de los arts. 1.17 y 1.18 de la Ley $25 / 2011$ de 1 de agosto, el art. 2.11 y 2.13 del RDL 9/2012 de 16 de marzo, y el art. 1 de la Ley 1/2012, de 22 de junio. El 30 de mayo de 2014, el Gobierno ha vuelto a presentar un nuevo Proyecto de Ley (el número 121/000097) por el que se vuelve a modificar la LSC para la mejora del gobierno corporativo, y también en mayo, se ha presentado el Anteproyecto de Código Mercantil, un proyecto ambicioso que viene gestándose desde 2006. Finalmente, el pasado 24 de diciembre entró en vigor la Ley 31/2014 de 3 de diciembre, por la que se vuelve a modificar la Ley de Sociedades de Capital para la Mejora del Gobierno Corporativo.

${ }^{4}$ Esta Ley es excepcional no sólo en cuanto a contenidos sino también en relación a la forma en que nace - Respecto a los contenidos, su propia Exposición de Motivos ya anticipa su voluntad de "provisionalidad" y que nace con "el deseo de ser superada pronto", intentando ser sólo "un peldaño más" de la escala hacia el progreso. Reconoce, asimismo, que el legislador debe en el futuro afrontar importantes reformas en la materia y revisar algunas soluciones legales tradicionales. En cuanto a la forma en que nace, también es excepcional: ésta Ley fue publicada en el BOE en pleno mes de agosto, histórico período de asueto.
} 
modificación, por mayoría, de los pactos estatutarios -con la finalidad de adaptar sus normas de funcionamiento a las cambiantes necesidades del tráfico-; y por otro lado, el interés del socio, que no votó a favor de este acuerdo, a no verse sometido al mismo por implicar una alteración sustancial de alguno de los elementos esenciales que, en su día, fueron determinantes para consentir su incorporación a la sociedad-. Se trata, pues, de una institución que faculta al socio disconforme con la modificación para disolver parcialmente el vínculo social. Por lo tanto, el ejercicio del derecho de separación, no provoca una disolución total de la sociedad que la conduzca a la extinción. La separación, sólo supone una ruptura del vínculo societario respecto del socio que ejercita su derecho de separación. Los demás socios, permanecerán vinculados por el contrato de sociedad ${ }^{5}$.

Es así que, en las sociedades de capital, el principio mayoritario y el interés de conservar el capital plantea un problema de equilibrio, de intereses enfrentados, totalmente distinto al que encontramos en las sociedades personalistas, pues en éstas últimas, el principio de gestión individual y la toma de decisiones por unanimidad son la garantía de los derechos individuales del socio.

Por lo tanto, en relación al fundamento del derecho de separación, en las sociedades de capital, existe un elemento clave que va a ser diferente al fundamento de este derecho en las sociedades personalistas. Ese elemento clave es que, en las sociedades de capital, el ejercicio del derecho de separación será "un elemento de defensa individual del socio" frente a determinados hechos ${ }^{6}$.

\subsection{Delimitación conceptual del de Derecho de Salida.}

La separación del socio es una figura legal que aparece por vez primera en el artículo 158 del Código de Comercio Italiano de 1882, aunque en España, nace en la Ley de sociedades anónimas de 1951 originándose como "medida compensatoria”, otorgada a los socios de sociedades de capital, para recompensarles por la pérdida de su posibilidad de veto, al sustituir la regla de la unanimidad por la de la mayoría. Más tarde, ésta figura legal, se extendió a otros tipos sociales. Sin embargo, a lo largo de los

\footnotetext{
5 SALVATORE: "Il nuovo diritto di recesso nelle societá di capital", Contratto e Impresa. 2003, pág. 629.

${ }^{6}$ BONARDELL LENZANO, R. y CABANAS TREJO, R.: Separación y exclusión de socios en la sociedad de responsabilidad limitada, Pamplona, Aranzadi, 1998, p. 25.
} 
últimos años, el derecho de separación del socio viene siendo objeto de un proceso de regresión en los ordenamientos extranjeros. En territorio español, este declive se ha apreciado en el ámbito de las sociedades anónimas, pero no en el de las sociedades de responsabilidad limitadas, donde la Ley vigente le otorga un amplio reconocimiento.

El derecho de separación es un derecho subjetivo, legal, concedido en abstracto, individual, inderogable ${ }^{7}$, irrenunciable ${ }^{8}$, indisponible, de carácter excepcional y en cierta medida, de naturaleza económico-patrimonial. Es un derecho de ejercicio expreso o tácito (por inactividad), total y voluntario. Es un derecho inherente a la condición de socio, pues contribuye a la exclusiva defensa de sus intereses. Es importante señalar que no es un derecho de minorías en sentido estricto, ya que su ejercicio no se vincula a la titularidad de una cuota determinada de capital social.

El derecho de separación o receso es aquél derecho que habilita al socio -sea éste mayoritario o minoritario- a "abandonar voluntariamente" la sociedad cuando cambien sustancialmente las condiciones establecidas en el contrato social al que en su día prestó consentimiento, siendo una manera de desvincularse unilateralmente de la relación societaria ${ }^{9}$. Esta extinción voluntaria de la condición de socio, sólo será posible "si concurren determinados presupuestos" legales o estatutarios que lo justifiquen. De hecho, el socio no podrá separarse por su simple voluntad aunque piense que los motivos que le llevaron a formar parte de la sociedad han desaparecido. Por lo tanto,

\footnotetext{
${ }^{7}$ En nuestra opinión, el derecho de separación del socio es un derecho inderogable y, en general, es irrenunciable, como lo son todos los derechos del socio reconocidos legalmente, en abstracto, para futuro o para todos los eventos en que pueden ser ejercitados; con algunas excepciones legales expresas muy concretas

${ }^{8}$ En Derecho comparado, el Cc. italiano establece expresamente el carácter irrenunciable del derecho de separación, en los numerosos supuestos que contempla, en especial tras la reforma de 2003, en que el derecho de separación se convierte en pieza clave para legitimar gran variedad de modificaciones estructurales, incluidas las heterogéneas. En el mismo sentido: GIRÓN TENA, Derecho de Sociedades Anónimas, Valladolid, 1952, p. 183, p. 184-185; VICENT CHULIÁ, Compendio, 3. ${ }^{a}$ ed., 1991, vol. 1. ${ }^{\circ}$, p. 753; AGUILERA RAMOS; MARTÍNEZ JIMÉNEZ; MARTINEZ SANZ; PERALES VISCASILLAS; BRENES CORTES, entre otros.

${ }^{9}$ Vid en este sentido la STS de 10 de marzo de 2011 que define dejar de ser socio como ".. peculiar fórmula de tutela de la minoría frente a la capacidad de los capitales de dominio para imponer por el juego de las mayorías y sin necesidad de pacto con los minoritarios, la modificación del objeto social, nuestro sistema autoriza a los disidentes a romper el vínculo con quiebra de la regla de irreversibilidad de la inversión y del principio de integridad del patrimonio de la sociedad, de la sociedad, y de forma similar a la prevista en el artículo 2437 del Código Civil italiano ..."
} 
tendrá que esperar a la materialización de alguna de las causas legales o estatutarias de separación y, únicamente después, podrá ejercitar su derecho. Si opta por la separación de la sociedad, se efectuará la liquidación de su parte en el haber social, sin necesidad de disolución de ésta, conllevando automáticamente la obligación de la sociedad de reducir capital por la cantidad abonada al socio, por lo que a veces puede ser un mecanismo de presión, sobre todo por parte de los accionistas mayoritarios, que ante determinadas situaciones puedan amenazar con abandonar la sociedad y ésta verse en dificultades para satisfacer esa prima de salida o por el perjuicio de reducir el capital que lleva asociado este derecho.

En todas las sociedades mercantiles los socios tienen derecho de separación ${ }^{10}$. Actualmente, este derecho, sus condiciones y sus efectos están definidos en los estatutos de la sociedad. En caso de que no se especifiquen las causas y el procedimiento, regirá la normativa general recogida en la Ley de Sociedades de Capital.

\subsection{Fundamento según el tipo societario.}

El derecho de separación tiene su fundamento en las SOCIEDADES DE PERSONAS como fórmula alternativa a la disolución de la sociedad, en aquellos casos en que un socio decida salir cuando la sociedad se ha constituido por tiempo indefinido (art $225 \mathrm{C}$ de $\mathrm{C}$ en relación con art $224 \mathrm{C}$ de $\mathrm{C}$ ), constituyendo un instrumento ideal para facilitar la salida del socio de la sociedad, sin acudir a la disolución. De este modo, se concilian los intereses de ámbas partes: de la sociedad que puede continuar su actividad sin desaparecer y los intereses del socio que puede abandonar la sociedad y poner fin así a su vinculación patrimonial con ella.

Sin embargo, es diferente la razón de ser en las SOCIEDADES DE CAPITAL, ya que su fundamento se basa no tanto en el carácter más o menos duradero de la sociedad, sino en la necesidad de proteger a la minoría. Esta protección se articula a través del derecho de separación del socio que cobra su sentido cuando la mayoría, legítimamente, modifica las reglas estatutarias generándose un marco regulador distinto al anterior que no se ajusta a las expectativas que hasta entonces tenían los socios minoritarios. Al

\footnotetext{
${ }^{10}$ Aunque la separación de un socio en una sociedad capitalista es un supuesto excepcional y reglado, dado el principio de estabilidad de capital que impide a los socios la desinversión y rescate de su aportación (lo que es distinto de que el socio transmita sus participaciones y por ello deje de ser socio).
} 
socio minoritario se le otorga la posibilidad de dejar la sociedad porque las circunstancias en las que se incorporó han variado y no está de acuerdo.

De cualquier forma, la aplicación práctica del derecho de separación tiene su hábitat natural en las sociedades cerradas, por la imposibilidad de que un socio transmita libremente sus participaciones o acciones y porque se quiere evitar la salida de cualquier socio si la sociedad no lo autoriza, además de pretender impedir que pueda ingresar un tercero sin el consentimiento de la compañía. Y dicho carácter puede estar presente tanto en la sociedad limitada por definición legal como en la sociedad anónima por pacto estatutario.

Pues bien cuando una sociedad de capital reviste dicho carácter cerrado debe reconocerse a los socios el derecho de separación como fórmula alternativa que permita abandonar la sociedad a los que no estén de acuerdo con las nuevas orientaciones propuestas. Por ello, se entiende que se reconozca este derecho tanto en la limitada como en la anónima, porque lo importante para reconocerlo no es la forma social sino LA ESTRUCTURA, abierta o cerrada que tenga, y dicha estructura no depende estrictamente de la forma sino de los "estatutos sociales" que la articulen.

Así, el derecho de separación en las sociedades de capital va a tutelar el interés de los socios minoritarios que no estén de acuerdo con las decisiones adoptadas por la mayoría de socios y que suponen un cambio fundamental en el escenario societario interno. No obstante, el reconocimiento de esta facultad al socio de una sociedad de capital puede entrañar problemas dentro y fuera de la sociedad: internamente, porque su admisión pone en tela de juicio el poder de la mayoría del capital social y externamente, porque en la anónima o en la limitada el ejercicio del derecho de separación puede conllevar la descapitalización de la sociedad en la medida en que la amortización de acciones o participaciones genera la reducción del capital y la consiguiente merma de las garantías de terceros. Por todo esto, el derecho de separación se acoge con gran cautela en las sociedades de capital.

\section{TENDENCIAS LEGISLATIVAS ACTUALES}

El legislador en el momento de configurar el actual sistema de sociedades de capital pretendió establecer una "coherencia tipológica" de manera que prevaleciera el tipo 
social de la sociedad anónima para las sociedades abiertas, mientras que se reservaba el de las sociedades de responsabilidad limitada para las sociedades de tipo cerrado. Sin embargo, esta adscripción se realizó con carácter prevalente, pero no excluyente, de forma que la posición jurídica del socio no depende exclusivamente del texto legal, sino que puede ser objeto de modulación en cuanto a sus derechos y obligaciones por vía estatutaria $^{11}$. Esta cuestión plantea en nuestro sistema societario una permanente necesidad de análisis del caso concreto para determinar el grado de cercanía o lejanía con el supuesto ideal previsto por el legislador para cada tipo social concreto.

Es así que, incluso durante el proceso de adaptación del Derecho societario español, con motivo del acceso de España a la entonces denominada Comunidad Económica Europea, existían ya voces autorizadas que propugnaban una clara reorganización de la tipología societaria $^{12}$. Al hilo de la armonización comunitaria a través de Directivas y Reglamentos europeos, el ordenamiento jurídico español se ha visto inmerso en un permanente proceso de modificación y reforma cuyo principal objeto es intentar solucionar las tradicionales barreras tipológicas entre sociedad anónima y sociedad de responsabilidad limitada, hecho que plantea serios problemas a la hora de determinar, el límite legal a las causas de separación del socio.

Las tendencias legislativas actuales parecen continuar, en relación al derecho de separación, esta orientación. Si la doctrina, en un momento determinado, hablaba de la tendencia reductora del derecho de separación voluntaria del socio, en razón de la disminución de los supuestos en que se reconoce este derecho anterior a la LSL 1995, en la actualidad, no podemos sino resaltar la tendencia contraria, es decir, "la ampliación de supuestos", no tan solo en las sociedades de responsabilidad limitada, sino también a las sociedades anónimas ${ }^{13}$.

\footnotetext{
${ }^{11}$ EMBID IRUJO, J.M., y MARTIINEZ SANZ, F., “Libertad de configuración...”, op. cit., p. 13.

${ }^{12}$ FERNÁNDEZ DE LA GÁNDARA, L. "El problema tipológico: la consagración del sistema dualista sociedad anónima-sociedad de responsabilidad limitada", RDS, núm. extr., 1994, p. 36; ROJO, A.: "Quo vadis ius societatum", en. ARROYO MARTIINEZ, I. (coord.), I Congreso nacional de Derecho Mercantil, Madrid, Guitas, 2006, p. 424.
}

${ }^{13}$ Vid., MARTNEZ SANZ, F " Causas de separación del socio." Op. cit., p. 31. 


\subsection{El abandono voluntario del socio en la Ley de Modificaciones Estructurales de las Sociedades Mercantiles}

La Ley 3/2009 de 3 de abril, de Modificaciones Estructurales de las Sociedades Mercantiles (en adelante, LMESM), vió la luz con el objetivo de incorporar a nuestro ordenamiento jurídico normativa comunitaria en materia de sociedades, además de incluir una serie de retoques normativos destinados, sin duda, a dar mayor coherencia a la LMESM en sí dentro de nuestro Derecho societario ${ }^{14}$.

Como resultado de esta reorganización del régimen jurídico general de las sociedades mercantiles, el derecho de salida vio incrementados sus supuestos legales en determinados procedimientos de restructuración legal que suponen un cambio en la organización interna y externa de la sociedad, significando la aprobación de esta Ley el punto de partida de la configuración actual del derecho de separación, tanto por la ampliación de casos legales en relación con modificaciones estructurales, como por la actualización de los textos normativos materiales que surgieron a partir de este texto legal.

\subsection{El socio disidente en la Ley de Sociedades de Capital}

El TRLSC contempla actualmente en el Título IX, Capítulo I (arts. 346 a 349) las causas legales y estatutarias de separación del socio. Esta norma se aplica a todas las sociedades de capital (art 1 LSC). El artículo 346 regulará las causas legales, el artículo 347 las causas estatutarias, el art. 348 el ejercicio del derecho de separación, el art 348 bis recogerá el derecho de separación en caso de falta de distribución de dividendos y el art. 349, regulará la inscripción del acuerdo de separación.

\footnotetext{
14 Concretamente incorporó la Directiva 2005/56/CE, relativa a las fusiones transfronterizas de las sociedades de capital, Directiva 2006/68/CE, por la que se modifica la Directiva 77/91/CEE del Consejo en lo relativo a la constitución de la sociedad anónima, así como al mantenimiento y modificaciones de su capital, y Directiva 2007/63/CE, por la que se modifican las Directivas 78/855/CEE y 82/891/ CEE del Consejo por lo que respecta al requisito de presentación de un informe de un perito independiente en caso de fusión o escisión de sociedades anónimas. En el caso de la Directiva de fusiones transfronterizas, se había rebasado ya el plazo otorgado por la Comisión Europea para transponerlo a nuestro ordenamiento jurídico. En particular, sobre estas modificaciones. MIQUEL RODRIGUEZ, J. "Las reformas en la Ley de Sociedades Anónimas", en. ARROYO, I., EMBID, J.M. y GÓRRIZ, C., Comentarios a la, Ley de Sociedades Anónimas, $2^{\mathrm{a}}$ ed., vol. I, Madrid, Tecnos, 2009, pp. 238 y ss.
} 
El TRLSC reconoce en el art 346.1 el derecho de separación de manera expresa en los supuestos de disconformidad del socio con los acuerdos de sustitución del objeto social, de prórroga y reactivación de la sociedad, así como aquellos que supongan la creación, modificación o extinción anticipada de la obligación de realizar prestaciones accesorias, aunque en este último caso la norma permite que los estatutos limiten o excluyan la posibilidad de desvincularse.

Por otra parte, el TRLSC establece una mayor protección al socio de la sociedad de responsabilidad limitada, al conferirle la posibilidad de separación, además de en los casos señalados, frente a los acuerdos de modificación del régimen de transmisión de las participaciones sociales (art. 346.2 TRLSC).

Recientemente, la Ley 25/2011, de 1 de agosto, de reforma parcial de la Ley de Sociedades de Capital y de incorporación de la Directiva 2007/36/CE, del Parlamento, Europeo y del Consejo, de 11 de julio, sobre el ejercicio de determinados derechos de los accionistas de sociedades cotizadas, ha incorporado dos importantes modificaciones en los casos de separación, entre ellas: en primer lugar, ha añadido una modificación a la letra a) del apartado 1 del artículo 346 quedando redactada de la siguiente forma “a) Sustitución o modificación sustancial del objeto social”, y en segundo lugar, introduce un nuevo artículo 348 bis que reconoce un nuevo supuesto de separación en caso de falta de distribución de dividendos ${ }^{15}$.

Posteriormente, la Ley 1/2012 de 23 de julio en su artículo primero, apartado cuarto, introduce una disposición transitoria a la Ley de Sociedades de Capital suspendiendo el artículo 348 bis hasta el 31 de diciembre de 2014, y, el Real Decreto-ley 11/2014, de 5 de septiembre, de Medidas Urgentes en Materia Concursal, además de modificar la Ley Concursal en materia de convenio y de liquidación concursal, con la finalidad de facilitar la continuidad de las empresas económicamente viables, ha introducido una

\footnotetext{
${ }^{15}$ BOE núm. 184, de 2 de agosto de 2011.
}

Esta Directiva tiene como finalidad facilitar y promover, en el ámbito de la Unión europea, el ejercicio de los derechos de información y voto de los accionistas de las sociedades cotizadas. A través de las normas contenidas en esta Directiva se aspira a garantizar que las juntas generales sean debidamente convocadas y que los documentos que deben presentarse a las mismas estén disponibles a tiempo para que todos los accionistas, con independencia de su lugar de residencia, puedan adoptar una decisión razonada en el momento de emitir el voto 
modificación en la LSC, ampliando hasta el 31 de diciembre de 2016 la suspensión del plazo para la aplicación de su artículo 348 Bis que regula el derecho de separación de los socios minoritarios como consecuencia de la falta de distribución de dividendos ${ }^{16}$.

Por último, el pasado 24 de diciembre entró en vigor la Ley 31/2014 de 3 de diciembre, por la que se vuelve a modificar la Ley de Sociedades de Capital para la Mejora del Gobierno Corporativo, reforma encaminada a evitar situaciones como las vividas actualmente en el seno de muchas sociedades cotizadas y con el fin de aumentar la confianza en accionistas e inversores. Para ello, se proponen diferentes medidas de modernización y mejora del Gobierno Corporativo de las sociedades de capital, cambios en los regímenes jurídicos reguladores de la Junta General de Accionistas, la Administración de la sociedad y la retribución de los Consejeros, contemplando, para ello, modificaciones en relación a reforzar el papel con carácter general de la Junta General de Accionistas y fomentar la participación accionarial (regular los distintos conflictos de interés entre los accionistas, prohibiendo para ello el voto a los accionistas beneficiados), o en relación a la impugnación de los acuerdos adoptados en Junta (la desaparición de la distinción entre acuerdos nulos y anulables, la ampliación del plazo para impugnar, que pasa de 40 días a 1 año y la necesidad de contar con el $1 \%$ del capital para poder ejercer la acción de impugnación) ${ }^{17}$. En cuanto a las modificaciones efectuadas en materia de Administración de la sociedad, éstas se centran principalmente en las sociedades cotizadas, con el fin de insistir en la necesaria garantía de aspectos tan importantes como "la transparencia" en los órganos de gobierno y que el accionista pueda tener "mayor control de la gestión". Así, se regula de forma más precisa, los

16 Con ésta modificación de la LSC se pretende conseguir: una mayor transparencia, que la remuneración se adecue a las prácticas y cuantías de mercado tal y como se indica en el Preámbulo VI de la Ley, se pretende establecer que las remuneraciones de los administradores reflejen adecuadamente la evolución real de la empresa y estén correctamente alineadas con el interés de la sociedad y sus accionistas y que se regule un procedimiento para la aprobación de las retribuciones.

\footnotetext{
${ }^{17}$ En materia de conflictos de interés, la Ley ofrece una solución innovadora estableciendo los siguientes mecanismos: para conflictos como la exclusión de socios, la transmisión de acciones o participaciones sujetas a restricciones legales o estatutarias, la asistencia financiera y la dispensa de la obligación de lealtad, entre otros, se generaliza la prohibición de derecho de voto por ser considerados como los casos más graves de conflicto de interés. No obstante, en las SA la citada prohibición de ejercitar el derecho de voto en los casos de exclusión y transmisión de acciones sólo será de aplicación cuando esté expresamente prevista en las correspondientes cláusulas estatutarias.
} 
deberes de los administradores (Deber de diligencia: deben tener una dedicación adecuada y la obligación de exigir y recabar la información necesaria para el cumplimiento de sus obligaciones. Deber de lealtad: su infracción no sólo determina la obligación de indemnizar el daño causado sino también la de devolver el enriquecimiento injusto).

Tanto el instituto de la separación como el de la exclusión de socios en la LSC (Titulo IX) se configuran a partir del régimen precedente de la sociedad limitada y fue objeto de un amplio debate en el proceso de elaboración del proyecto. El dictamen del Consejo de Estado entendió adecuado el criterio de armonización, aunque profundizó especialmente en tres aspectos: el cuadro general de causas de separación del art. 346, que consideró amparado por el objetivo de la refundición; el alcance de las cláusulas estatutarias de separación y exclusión (art 347 y 351), donde las sugerencias fueron atendidas en materia de exclusión, que quedó referida a la sociedad limitada en exclusiva pero no en materia de separación, que se mantuvo generalizada; las actuaciones exigidas para la separación y exclusión, que estimó correctamente armonizadas.

En la Ley de Sociedades de Capital se entrecruzan aspectos básicos de esta rama del ordenamiento jurídico y, más específicamente, del eterno conflicto entre las visiones contractual e institucional del fenómeno societario, así como, de la vertiente propia de la tipología ${ }^{18}$. Podría decirse que el predominio de una visión contractual del derecho de sociedades, como sucede en nuestros días, está propiciando una consideración más amplia del derecho de separación, en tanto que la perspectiva institucional, hoy menos

\footnotetext{
18 Algunos autores italianos recientes hablan de una convivencia de la teoría contractualista con un neoinstitucionalismo: MONTALENTI P., "La societá quotata”, Padua, Cedam, 2004, pág. 62; id., "Amministrazione e amministratori nella riforma del diritto societario", en RESCIGNO, M., y SCIARRONE ALIBRANDI, A. (coords.), "Il nuovo diritto delle società di capitali e delle società cooperative", Milán, Giuffrè, 2004, págs. 61-62; id. , "Interesse sociale e amministratori”, en AA.VV., "L’interesse sociale " op. cit, 2010, págs. 99-100; COSSU, M., "Società aperte e interesse sociale", Turín, Giappichelli, 2006, especialmente pág. 312. Vid. también a QUIJANO GONZÁLEZ, J., y MAMBRILLA RIVERA, V., "Los deberes fiduciarios de diligencia y lealtad. En particular, los conflictos de interés y las operaciones vinculadas”, en AA.VV., Derecho de Sociedades Anónimas Cotizadas. (Estructura de Gobierno y Mercados), Tomo II, Navarra, Aranzadi, 2006, pág. 956.
} 
atendida por los autores, está reduciendo su alcance. La postura contractual, en ausencia de una mayor claridad normativa, es sin duda la seguida por la jurisprudencia ${ }^{19}$.

En la LSC la nueva configuración del derecho de separación del socio, tanto en la SA como en la SL, es reflejo fiel de la tendencia actual impulsada por los operadores económicos, y de los cuales el legislador ha sido fiel oyente, en cuanto a favorecer el entrecruzamiento de esquemas de organización, apartándose de las formas societarias puras. Así es comprensible que la tendencia legislativa haya significado la simplificación de los diversos mecanismos reguladores y diferenciadores de los tipos societarios ${ }^{20}$. Fruto de esta falta de criterios unitarios, es posible hablar en la actualidad de una forzosa revisión del fundamento del derecho de separación y de amplios debates doctrinales (límites a la autonomía de la voluntad).

Si con anterioridad partíamos de una base prácticamente uniforme, en la actualidad ha devenido o puede devenir en llegar a ser el derecho de separación del socio en un instrumento polifuncional que no obedece ya a un criterio único -cual era la necesidad de otorgar al socio minoritario un camino de salida cuando la sociedad hubiera adoptado determinados acuerdos que hacen inexigible su permanencia en ésta o cuando ocurriera un determinado hecho acordado unánimemente por los socios-, sino que obedecerá, en cada caso, a diversas finalidades específicas, cuyo único factor común será que efectivamente quienes lo ejerzan dejarán de ser miembros de una sociedad de capital ${ }^{21}$.

Otra consecuencia de esta "reunificación" desordenada de tipos, es que en la actualidad uno de los principales fundamentos de la limitación a los supuestos que activan el derecho de separación, cual es el principio de conservación del capital social, ha entrado en franco retroceso. En efecto, fruto de la crisis del capital social como garantía última

\footnotetext{
${ }^{19}$ Destacamos entre otras, la STS núm. 120/1991 (Sala de lo Civil), de 19 de febrero, las SSTS (Sala de lo Civil) núm. 825/1998, de 18 de septiembre; núm. 193/2000, de 4 de marzo; núm. 1131/2002, de 29 de noviembre; núm. 186/2006, de 7 de marzo; núm. 400/2007, de 12 de abril; núm. 1229/2007, de 29 de noviembre; núm. 873/2011, de 7 de diciembre; y la núm. 991/2011, de 17 de enero de 2012.

20 En ocasión de la actualización del régimen jurídico de la sociedad de responsabilidad limitada, ya había apuntado FERNÁNDEZ DE LA GÁNDARA, L. «El problema tipológico...», op. cit., p. 41, a la tendencia a desdibujar las fronteras funcionales entre la anónima y la limitada, al margen de toda coherencia sistemática interna y sin otra finalidad que resolver problemas prácticos concretos

${ }^{21} \mathrm{Si}$ finalmente el art. 348.bis vuelve a entrar en vigor a partir del 31 de diciembre de 2016 conforme está configurado
} 
de los acreedores sociales, las empresas que se organizan jurídicamente a través de una sociedad de capital, acceden a un modelo de financiación externo -ajeno- al capital social, de manera que en realidad, la estabilidad que persigue el principio de conservación del capital social, ha visto debilitada su importancia en favor de criterios más acordes con los procesos de financiación de estos días. Siendo ésta, a nuestro entender, quizás no la única, pero posiblemente una de las más importantes razones por las cuales el derecho de separación ha incrementado el número de sus supuestos, tanto en la SA como en la $\mathrm{SL}^{22}$.

Por otra parte, la inclusión expresa de causas estatutarias de separación en la SA es otro ejemplo del incremento del derecho dispositivo en el ámbito de la sociedad anónima, que no se circunscribe, a las sociedades anónimas cerradas, sino que puede también ser de aplicación a sociedades abiertas. No debemos olvidar que solamente el art. 348.bis TRLSC excluye expresamente su aplicación a las sociedades anónimas cotizadas, de manera que todos los supuestos legales y convencionales de separación pueden aplicarse, hipotéticamente, a las sociedades abiertas. De manera que en uno u otro tipo de causa de separación, para encontrar un límite -sobre todo en el caso de las cláusulas estatutarias que reconozcan el derecho del socio a separarse- habrá que tener en cuenta tanto el art. 28 TRLSC, como el art. $1.256 \mathrm{CC}^{23}$.

\footnotetext{
${ }^{22}$ Es ineludible mencionar que este elemento principal del régimen de las sociedades se encuentra en el centro de las fundamentaciones que dan razón de ser y constituyen el límite lógico a la fundamentación de las causas de separación del socio. En este sentido, creemos que la ampliación de estos supuestos surgen de la mano, por un lado, de la ya mencionada "dilución tipológica" de las sociedades de capital cerradas, pero también de la crisis del sistema de capital social (sobre este tema en concreto, vid., por ej., ALONSO LEDESMA, C., "Algunas reflexiones sobre la función (la utilidad) del capital social como técnica de protección de los acreedores", en AAVV, Estudios de Derecho de sociedades y Derecho concursal. Libro homenaje al profesor Rafael García Villaverde, vol. I, Madrid, Marcial Pons, 2007, p. 127 y ss.).
}

${ }^{23}$ A favor de esta interpretación: EMBID IRUJO, J.M. Grupos de sociedades y accionistas minoritarios. La tutela de la minoría en situaciones de dependencia societaria y grupo, Ministerio de Justicia, 1987, pp. 148 y ss.; MARTINEZ SANZ, F. La separación del socio..., op. cit., p. 18, más recientemente, FERNÁNDEZ DE LA GÁNDARA, L. Derecho de sociedades, vol. II, op. cit., p. 1890, destaca positivamente los efectos disuasorios que el reconocimiento de este derecho puede tener en favor de los socios minoritarios, pues de esta manera el órgano de administración deberá buscar fórmulas de consenso en la toma de decisiones, con el fin de tener el menor número posible de disidentes, por su parte, PEINADO GRACIA, J.I.; GONZÁLEZ FERNÁNDEZ,, V..M.B. «Sistemática y clasificación de los derechos del accionista en la sociedad cotizada», en PEINADO GRACIA, J.I. y CREMADES GRACIA , J. (dirs.), El accionista minoritario en la sociedad cotizada (Libro blanco del accionista minoritario), Madrid, La Ley, 2012, p. 88, incluye el derecho de separación ente los derechos instrumentales o de desarrollo de los derechos individuales de los socios, mientras que M. ENCISO ALONSO-MUNUNIER, «La tutela de los accionistas minoritarios en sociedades 
Anteriormente, las causas legales de separación estaban configuradas como un mecanismo protector de los intereses del socio que no estuviera de acuerdo con determinado tipo de acuerdos sociales, sobre todo relacionados con la eliminación o modificación de los derechos administrativos y políticos del socio. Sin embargo, es previsible que esta unidad de función, en el futuro amplíe su base protectora para incluir también los derechos económicos, o cuales quiera otros a los que el legislador decida darles ésta posibilidad de negociación ${ }^{24}$.

Esta ampliación de la naturaleza jurídica del derecho de separación podría atentar contra el principio de conservación de la empresa, que ha sido, sin duda, la piedra angular en la que se basa este instrumento jurídico y el elemento clave en el mantenimiento de los intereses de naturaleza diversa que deben ser protegidos y que a su vez hasta ahora han servido de límite a las causas legales de separación. (En contra, Vid. Jesús.Alfaro El "principio de conservación y estabilidad del capital" no es una norma imperativa. Ni siquiera es un principio obtenido por inducción de un conjunto de normas. Más bien, de las normas sobre aumento y reducción del capital lo que se deduce es un principio de "variabilidad" del capital. Por tanto, no vale como argumento para limitar la libertad estatutaria).

En relación a las causas estatutarias de separación, el grado real de transmisibilidad de las participaciones sociales y acciones, tanto de la SA como de la SL, sigue siendo crucial a la hora de justificar esta ampliación del derecho de separación, puesto que es precisamente la preponderancia de sociedades cerradas entre las sociedades anónimas, la razón práctica de mayor relevancia, que ha llevado al legislador a reconocer que también en este tipo social es necesario un mayor grado de libertad estatutaria.

filiales cotizadas», en PEINADO GRACIA, J.I. y J. CREMADES GRACIA (dirs.), El accionista minoritario..., op. cit., p. 494, incluye al derecho de separación como una de las medidas específicas de tutela del socio minoritario en la sociedad filial cotizada.

${ }^{24}$ Cuestión que, a nuestro entender, habría requerido una reforma legal más amplia que su simple inclusión como causa legal de separación en los términos que actualmente regula el art. 348.bis TRLSC 


\section{LA FALTA DE DISTRIBUCIÓN DE DIVIDENDOS COMO PUERTA DE SALIDA DEL INVERSOR MINORITARIO}

En los actuales tiempos de grandes dificultades económicas, las sociedades que han venido operando en el mercado económico han sufrido un importante desgaste que se ha transmitido, en gran parte de los casos, a las relaciones entre los socios y entre estos y los miembros de los órganos de administración.

Así, no ha sido infrecuente encontrarnos con numerosos supuestos en los que las relaciones intrasocietarias entre los propios socios han llegado a una situación de no retorno y en los que, en la mayoría de los casos, se han venido solucionando a favor de los socios que representan la mayoría del capital social que puede, a través de dicha situación de superioridad, articular una serie de mecanismos que, salvaguardando los intereses de los socios que componen esa mayoría del capital social, perjudicando los intereses, económicos o de cualquier otro tipo, que los socios perjudicados por la situación de minoría en que se encuentran pueden mantener o prever en la sociedad.

En gran parte de los supuestos en los que se da este tipo de conflictividad social, el recurso más evidente sería el de la salida de los socios minoritarios de la sociedad en la que no están viendo satisfechas sus pretensiones ni intereses. El problema es que la salida de la sociedad implica, necesariamente, que otra u otras personas adquieran la participación que los socios minoritarios mantienen en la sociedad lo que, en muchas ocasiones, no puede darse puesto que no suele darse un exceso de demanda de participaciones minoritarias en sociedades mercantiles. Por ello la convivencia en aquellas sociedades en las que se dan casos de conflictividad social resulta muy complicada lo que, con las limitaciones señaladas anteriormente, suele llevar a las partes más afectadas por dicha situación (los socios minoritarios de la sociedad) al intento de salir de la sociedad.

De este modo, fuera de los casos que a Ley venía recogiendo y que, en la práctica, eran muy limitados, los socios que forman esa minoría societaria y que veían, sistemáticamente, como la mayoría del capital social utilizaba esa situación de preeminencia para perjudicar sus intereses, solamente podían acudir a cláusulas estatutarias de salida que, en la mayor parte de los supuestos, no habían sido introducidas ni previstas. 
Es así que con la Ley 25/2011 de 1 de agosto de reforma parcial de la Ley de Sociedades de Capital y de incorporación de la Directiva 2007/36/CE del Parlamento Europeo y del Consejo de 11 de julio, sobre el ejercicio de determinados derechos de los accionistas de sociedades cotizadas, se incorporó ésta pretensión de los socios minoritarios, cual es la configuración legal, bajo determinadas condiciones, de un derecho mínimo al reparto de dividendos, y cómo su denegación por la mayoría social en junta general puede dar lugar al ejercicio del derecho de salida voluntaria para la minoría, evitando con ello situaciones de cautividad social de la minoría por parte de la mayoría $^{25}$.

El actual artículo 348 bis TRLSC regula el derecho de separación en caso de falta de distribución de dividendos en determinados supuestos, estableciendo:

"1. A partir del quinto ejercicio a contar desde la inscripción en el Registro Mercantil de la sociedad, el socio que hubiera votado a favor de la distribución de los beneficios sociales tendrá derecho de separación en el caso de que la junta general no acordara la distribución como dividendo de, al menos, un tercio de los beneficios propios de la explotación del objeto social obtenidos durante el ejercicio anterior, que sean legalmente repartibles.

2. El plazo para el ejercicio del derecho de separación será de un mes a contar desde la fecha en que se hubiera celebrado la junta general ordinaria de socios.

3. Lo dispuesto en este artículo no será de aplicación a las sociedades cotizadas."

La falta de reparto de dividendos como nuevo supuesto de separación legal incorporado a la LSC en el art 348 bis ha sido muy controvertido en los últimos tiempos. Desde la introducción del nuevo precepto en la Ley de Sociedades de Capital, la crítica del contenido y oportunidad del mismo ha sido muy relevante. Así, desde sectores

25 Hasta la aprobación de la presente reforma, la jurisprudencia menor había venido reconociendo de una forma más bien tímida el derecho al dividendo. Sentencias como la de la Audiencia Provincial de Barcelona de 21 de enero de 2011, o la de la Audiencia provincial de Baleares de 20 de diciembre de 2010 habían declarado abusiva la retención sistemática del reparto de dividendos cuando existen reservas voluntarias suficientes que justifican que la empresa se encuentra saneada financieramente. 
doctrinales, jurisprudenciales $\mathrm{y}$, sobre todo, desde el sector empresarial del país, se cuestionó la conveniencia de otorgar este derecho a los socios minoritarios, más aún en el momento en que fue introducido, en el que el país se encontraba sumido en una importante crisis económica donde la posibilidad de las sociedades para acceder al crédito eran muy limitadas o, en la mayoría de los casos, inexistentes, por lo que si además debían pagar dividendos o reembolsar las participaciones de un socio saliente, la situación se volvía en muchos casos crítica, abocando a la sociedad obligada al pago de cualquiera de los dos conceptos a una situación de insolvencia.

Por ello, y en vistas a la situación creada y a la oposición de importantes sectores de opinión, en fecha 22 de junio se promulgó la Ley 1/2012 (RCL 2012, 870) de simplificación de las obligaciones de información y documentación de fusiones y escisiones de sociedades de capital, en la que se procedía a suspender, hasta el 31 de diciembre de 2014, la aplicación de lo dispuesto en el artículo 348 bis de esta Ley. Es decir, durante el plazo de dos años y medio, el nuevo derecho de separación otorgado al socio quedaba suspendido con lo que este veía, nuevamente, frustradas sus opciones de oponerse a los acuerdos referidos a la distribución de dividendos adoptados por la mayoría. Posteriormente dicha suspensión ha vuelto a ser ampliada hasta el 31 de diciembre de 2016, según Real Decreto-ley 11/2014 de 5 de septiembre (BOE No 217, lo cual parece indicar que a fecha de hoy, el legislador sigue sin encontrar una solución.

Una de las cuestiones que llama poderosamente la atención es plantearnos el por qué se le da por una parte un "empujón" al artículo y por otra "no se le deja entrar en vigor". Pudiera pensarse que el legislador desea establecer alguna disposición favorable al socio minoritario, ya que, si el minoritario no recibe beneficios ni puede intervenir en las decisiones de la sociedad, su participación o acción podría carecer de utilidad, pero el legislador no está todavía muy convencido de qué es lo que puede hacer a favor de tal tipo de socios. Así que podríamos interpretar que, para no olvidar esa tarea pendiente, la deja hasta el 1 de enero de 2017 en que a falta de mejor solución se aplicaría esta técnica legislativa. También pudiera interpretarse que con la última suspensión de dos años se quisiera tener en cuenta dos hechos:

- La Aprobación del nuevo Código Mercantil que dejará sin efecto el redactado actual del art. 348 bis LSC durante el año 2015 y 
- La consolidación de la "recuperación económica" durante este período.

En cuanto a la voluntad de aprobar una disposición favorable para los socios minoritarios, parece claro que es la intención del Gobierno. No obstante, como ya han comentado varios autores, entre ellos el mismo Jesús Alfaro, el socio minoritario no necesita este artículo al poder defender su derecho a dividendos en base al abuso de la mayoría. (Recientemente, Sentencia de la Audiencia Provincial de Madrid de 3 de febrero de 2.013, que reconoce el derecho de los socios minoritarios a percibir dividendos, considerando abusivo el acuerdo de aprobar la aplicación de la totalidad del beneficio a reservas voluntarias, en perjuicio del reparto de dividendos entre socios, o la Sentencia de la Audiencia Provincial de Girona de 21 de marzo de 2013).

No obstante, para analizar detenidamente en éste epígrafe las causas que han llevado a la incorporación de este supuesto concreto de separación, creemos importante mencionar la posición que el ánimo de lucro ocupa dentro del régimen jurídico general de la sociedad en contraposición a la justificación que ha servido para incluir esta nueva causa legal de separación, cual es el tratamiento de los comportamientos abusivos de las mayorías en las sociedades de capital, en particular en relación a los derechos económicos de los socios minoritarios, para así ofrecer un panorama completo del contexto en el que se ha introducido esta nueva causa de separación legal y exponer las razones por las cuales encontramos que este nuevo supuesto no toma en cuenta importantes aspectos relacionados con la organización interna de las sociedades de capital. Cuestión que causa un desequilibrio sin precedentes en ocasiones en favor de unos socios, no necesariamente minoritarios, pero que debido a la falta de otros mecanismos que salvaguarden sus derechos económicos concretos, han merecido la protección legal de sus intereses a través de su inclusión en el TRLSC como causa de separación y de consolidar su vigencia en nuestro ordenamiento jurídico, podría ocasionar un deterioro patrimonial capaz de avocar a la sociedad a su disolución.

\subsection{El ánimo de lucro}

Tradicionalmente, un sector doctrinal ha reconocido que el ánimo de lucro es un elemento característico de los contratos asociativos en Derecho privado. A pesar de ello, este ánimo de lucro, si bien puede formar parte de los fines sociales, en nuestra opinión, no forma parte de la causa del contrato de sociedad, puesto que, de ser así, la falta de fin lucrativo en las sociedades de capital debería determinar la nulidad de la sociedad. A fin 
de restablecer la coherencia necesaria para el funcionamiento del sistema, ha sido necesario interpretar los preceptos legales de ámbito general, en perspectiva de las más recientes normas de ámbito societario especial, que identifican, consecuentemente, a esta finalidad lucrativa como una opción entre otras de las que pueden desarrollar las sociedades mercantiles, pero no como un requisito de validez de las mismas ${ }^{26}$.

Dicho fin lucrativo tiene su expresión en el reconocimiento legal de los llamados derechos económicos del socio, los cuales expresan sin duda la voluntad legal de asegurar, a quienes hubieran aceptado formar parte de la sociedad, un rédito a esa aportación económica sin la cual el vínculo jurídico con la sociedad no se puede dar por existente. No obstante, estos derechos económicos no son, o al menos de momento no han sido $-\mathrm{y}$ creemos que no deberían ser- objeto de concreción por parte del legislador, pues si bien es cierto que respecto del derecho a la cuota de liquidación, el art. 93.a) TRLSC (anteriormente art. 48.2 LSA), no deja lugar a dudas sobre la participación del socio en el patrimonio resultante de la liquidación, la cuantía de ésta se conocerá solamente una vez se hubiera concluido el procedimiento previo de disolución y liquidación de la sociedad. De forma que en ningún caso puede conocerse, con antelación, si ésta estará constituida por un derecho de crédito o una obligación de pago.

A una indeterminación similar se encuentra sujeta el derecho a participar en las ganancias sociales, pues para que esta obligación abstracta se materialice, corresponde a la junta general pronunciarse respecto del beneficio distribuible en cada ejercicio, de manera que el derecho de crédito del socio surgirá, cuando además de aprobarse unas cuentas anuales de las que resulten beneficios, la junta acuerde su reparto.

Pueden, sin duda, encontrarse ejemplos de concreción de los derechos económicos del socio en el Derecho Comparado, sobre todo en relación a sociedades abiertas, pero no en el caso de sociedades cerradas en las que la tónica general es dejar en manos de la mayoría la aprobación del reparto de beneficios.

\footnotetext{
${ }^{26}$ PAZ-ARES, “Animo de lucro y concepto de sociedad”, op. cit., p. 749, puntualizaba que la única manera coherente de entender que el ánimo de lucro es el elemento causal inamovible del contrato de sociedad, traería como consecuencia que su falta determinara la ajuricidad o la antijuridicidad, de todos los contratos de sociedad que no se adscribieran a este fin, cuestión que en el primer caso supondría una grave conculcación del principio de autonomía privada (art. 1.255 CC), y en el segundo del principio constitucional de libre asociación (art. $22 \mathrm{CE}$ ).
} 
A pesar de ello, la tendencia jurisprudencial a la protección de este derecho del socio, ha ido estableciendo una doctrina interpretativa del mismo que reconozca los casos de abuso de las mayorías en cuanto a la ausencia sistemática de reparto de dividendos cuando no media para ello justificación económica que amerite la ausencia del reparto ${ }^{27}$. Así pues, hasta antes de la Ley 25/2011, de 1 de agosto, los derechos económicos del socio no habían sido objeto de concreción obligatoria por parte del legislador. La justificación de esta postura se había basado en la libertad de gestión que el legislador constitucional ha reconocido a las entidades de Derecho privado en la gestión de sus asuntos. En todo caso, si llegara a regularse este derecho, correspondería hacerlo a través de la concreción de los derechos económicos del socio en el art. 93 TRLSC o en todo caso en relaciónala capacidad/obligación de la junta general de aprobar el reparto de beneficios (art. 273 TRLSC).

\subsection{El abuso de las mayorías}

Los conflictos entre socios mayoritarios y minoritarios de una sociedad mercantil ha sido uno de los problemas de más difícil resolución para el legislador español debido a la dificultad relativa a la concreción legal del concepto en sí, dada la amplitud de los supuestos de diversa naturaleza que desencadenan los elementos protectivos previstos por el legislador ${ }^{28}$.

Sin embargo, la existencia de un conflicto de interés permanente en la sociedad no es motivo suficiente como para justificar una activa intervención legislativa. Con mayor razón en el caso de nuestro ordenamiento jurídico, donde la configuración polifuncional de los tipos sociales, tanto en la sociedad anónima como en la sociedad de responsabilidad limitada, hacen que sea mucho más difícil prever mecanismos equilibrados que, cumplan el objetivo de amparar a aquellos socios que ven

\footnotetext{
${ }^{27}$ Con amplias referencias al tratamiento jurisprudencial de este supuesto, ALFARO ÁGUILAREAL, J. y CAMPINS, A.B.: "El abuso de las mayorías en la política de dividendos. Un repaso por la juisprudencia", Otrosí núm. 5, 2011, pp. 19 y ss.
}

${ }^{28}$ GARRIGUES, J. «La protección de las minorías en el Derecho español», RDM, núm. 72, 1959, pp. 249 y ss. 
desprotegidos sus intereses en detrimento de mayorías institucionales o minorías $\operatorname{organizadas}^{29}$.

Aún así, no hay que perder de vista que la protección de las minorías, tal y como se encuentra articulada en la actualidad, viene unida a su cualificación como tal, pues de otra manera entraríamos en el ámbito de los derechos individuales del socio, los cuales pueden ser ejercidos independientemente del porcentaje de capital social que éste represente y que en todo caso protegen la legalidad de determinadas actuaciones sociales, mientras que los derechos de minoría no sólo cumplen con esta labor, sino que también contribuyen a mantener la estabilidad societaria.

Por otra parte, también hay que tener en cuenta que hasta ahora los derechos objeto de protección por esta vía habían alcanzado sobre todo al ámbito administrativo y de gestión de los asuntos sociales y no así el de los derechos económicos, debido a la necesidad de otorgar suficiente libertad a los órganos sociales para que sean éstos quienes tomen las decisiones empresariales para asegurar la consecución del fin social.

Finalmente, dentro de los supuestos posibles de abuso de la mayoría, la retención injustificada de beneficios puede considerarse un ejemplo evidente de la misma, añadiéndose a ello la precariedad de los mecanismos de defensa del socio minoritario, pues a la necesidad de una constante y costosa actuación judicial se ha de sumar la necesidad de justificación de dicha actuación como la única vía que permita al minoritario acceder a este derecho que la mayoría le niega ${ }^{30}$.

\subsection{Falta de distribución de beneficios como causa de abandono en el Derecho Comparado .}

En el Derecho Comparado, el supuesto de abandono voluntario del socio por falta de distribución de beneficios tampoco es nuevo ni extraño, sino que viene siendo un

\footnotetext{
29 JUSTE MENCIA, J. Los derechos de minoría..., op. cit., p. 41, resaltaba el efecto gravoso que el principio mayoritario adquiere cuando merced a la creación de grupos estables de interés, los socios minoritarios se ven forzosamente sujetos a la voluntad de otros.
}

${ }^{30} \mathrm{Vid}$. la jurisprudencia citada respecto de este supuesto por IRACULIS ARRREGUI, N. "Impugnación del acuerdo de no repartir dividendos: atesoramiento abusivo de los beneficios", RDM, 261, 2011, p. 260. 
elemento habitual de los derechos del socio, que lleva aplicándose con éxito tanto en ordenamientos jurídicos de tradición civilista como del common law. Sin embargo, en la legislación comparada, un primer "mecanismo de control del abuso" que este derecho de la mayoría puede tener se encuentra en los "deberes de lealtad y fidelidad", tanto de los socios entre sí, como de los administradores sociales.

En el caso del Derecho alemán, es ésta falta de lealtad de los socios mayoritarios el elemento clave para la declaración judicial de separación del socio, criterio que recae dentro de los justos motivos reconocidos judicialmente como requisito necesario para permitir la separación del socio. Sin embargo, ni en legislaciones como la británica o la alemana, se ha llegado a incluir una causa legal de separación como la que señala el art. 348.bis TRLSC.

Así pues, en ambos ordenamientos jurídicos a pesar de pertenecer a tradiciones jurídicas muy distintas, puede observarse el mantenimiento de un elemento común, en cuanto a la consecuencia del ejercicio del derecho de separación del socio, y es que éstos ordenamientos jurídicos no suelen disminuir el capital de la sociedad como consecuencia de la salida del socio disidente, sino que la resolución judicial pertinente determinará si quien ha de adquirir la participación del socio es, como en la mayoría de los casos británicos, otro u otros socios mayoritarios o la sociedad en sí, con cargo a reservas distribuibles Podemos decir, entonces, que en ámbos casos se observa un meticuloso respeto al Principio de Conservación del Patrimonio Social.

Finalmente, se ha comentado favorablemente la posible inclusión de una regulación similar a la que incluye el art. 348. Bis en el proyecto de sociedad privada europea. Sin embargo, habría que tener en cuenta que este texto, lejos de estar consolidado y en proceso de adopción definitiva, aún se encuentra sujeto a modificaciones y reformulaciones de su contenido. En la última propuesta del Consejo en esta materia, el nuevo articulado propone la eliminación tanto del art. 18 sobre el derecho de separación, como el del art. 17 sobre la exclusión del socio. En ambos casos se propone su regulación en las cláusulas estatutarias de la sociedad, precisamente por el alto grado de animadversión que estos artículos suscitaban entre diversos EEMM.

En España, la acumulación de beneficios en detrimento de determinados socios ha sido un tema recurrente en diversos proyectos legislativos, así como de diversos pronuncia- 
mientos doctrinales ${ }^{31}$. Sin embargo, en la mayor parte de los casos, la solución judicial ha partido de la impugnación de los acuerdos sociales de no repartir dividendos (STS de 30 de enero de 2002), en el entendido que la conducta antijurídica parte de la aprobación, por parte de la junta general, de la propuesta de los administradores sociales de no reparto de dividendos ${ }^{32}$.

Una interpretación literal del nuevo supuesto, atentaría contra la libertad contractual de los socios y pondría en peligro la función productiva del capital social, al obligar a la sociedad a repartir beneficios, incluso, cuando todos los socios estuvieran de acuerdo en no hacerlo. Se provocaría una descapitalización obligatoria que, en ningún caso, puede considerarse como fin último del nuevo precepto legal ${ }^{33}$.

Finalmente, y a nuestro entender, la justificación de este supuesto como elemento clave de la tutela de la minoría respecto del abuso por parte de los socios mayoritarios no puede convertirse en un principio normativo de acogimiento tan intenso que lleve a una perversión de los elementos que constituyen su sistema de protección.

\subsection{Problemática de interpretación}

En relación a los problemas de interpretación suscitados, según la redacción actual del art. 348 bis TRLSC, creemos indiscutible la imperatividad e inderogabilidad del mismo, no sólo porque del texto literal de la norma a estudio no puede deducirse su derogabilidad estatutaria, sino porque el configurar esta obligación de reparto de dividendos como causa legal de separación tiene como consecuencia incluirla en el

\footnotetext{
${ }^{31}$ Así una de las propuestas de ley de la LSL 1995 proponía incluir esta obligación de reparto de dividendos, mientras que la PCSM, señalaba la posibilidad de separación por esta causa además de prever una causa específica en el caso de los socios externos en los grupos de sociedades (art. 599

32 En concordancia con esta interpretación el Tribunal Supremo en diversas ocasiones se ha pronunciado en torno a este derecho económico, calificándolo de derecho abstracto, STS de 30 de enero de 2002 (RJ 2002/231 1).

33 Al respecto, no podemos dejar de mencionar la RDGRN de 22 de noviembre 1991 (RJ 1991/8637), a través de la cual se determinó como válida una cláusula estatutaria que establecía la obligatoriedad de destinar parte de los beneficios anuales a realizar donaciones a las fundaciones promovidas por la sociedad. También hay que tener en cuenta que en proyectos de financiación empresarial, una obligación frecuente impuesta por las entidades financiadoras es, precisamente, la obligación de no repartir dividendos durante el periodo de vigencia de la financiación, en cuyo caso se estaría hablando de un periodo no inferior a cinco o diez años.
} 
catálogo de derechos individuales de los socios, viniendo a expresar una injustificada preferencia de los intereses individuales del socio sobre el interés social.

Respecto a los problemas concretos que el supuesto plantea, llama poderosamente la atención que el legislador no haya incluido referencia alguna para delimitar la aplicación de este supuesto exclusivamente a los casos de abuso de la mayoría. Al no realizarse esta acotación, entendemos que su aplicación es innegable y se extiende a "todas las juntas generales ordinarias en las que no se apruebe el reparto de dividendos", cuestión que traería como consecuencia, que transcurridos los cinco años señalados por ley, anualmente podría darse el caso de que algún socio decidiera separarse de la sociedad, con las consiguientes consecuencias económicas para el patrimonio social ${ }^{34}$.

\footnotetext{
${ }^{34}$ Vid, STS de 26 de mayo de 2005 que consideró como una actuación abusiva privar al socio minoritario, sin causa acreditada alguna, de su derecho a percibir los beneficios sociales obtenidos y proceder a su retención sistemática. En el mismo sentido, las SAP de Murcia de 28 de noviembre de 2008 (AC 2009, 122), y de 27 de febrero de 2009 (JUR 2009, 237051) consideran incardinable jurídicamente en el abuso de derecho acuerdos relativos al no reparto de dividendos adoptados en Juntas Generales Extraordinarias de una sociedad anónima; y la SAP de Madrid (Sección 19') de 7 de octubre de 2005 (JUR 2005, 252346) declara que congelar ilimitadamente el reparto de beneficios supone un daño grave para los intereses de la minoría con manifiesta infracción del artículo 7.2 CC, pues en una sociedad como la anónima, capitalista por excelencia, el reparto de dividendos es esencial en su propia configuración legal. También la Sentencia de la Audiencia Provincial de Málaga (Sección 6 ${ }^{\mathrm{a}}$.), de 27 de abril de 2007 JUR 2008, 18258), entiende difícilmente la constitución de una sociedad mercantil que no tienda a practicar reparto de dividendos entre sus socios, convirtiendo la totalidad de sus ganancias en reservas voluntarias. Por ello, declara como abuso de derecho la política de retención de beneficios por carecer de justificación ni en el Acta de la Junta General ni en la Memoria de Cuentas presentadas. El criterio de esta Sentencia es que carece de justificación que las reservas cuadripliquen la cifra del capital social cuando no existe previsión de inversión o gasto extraordinario.
}

En cambio, la SAP de León (Sección $2^{\mathrm{a}}$ ), de 6 de junio de 2003 (JUR 2004, 11320), no considera abusivo un acuerdo en el que se decide imputar la totalidad de los resultados obtenidos a reservas voluntarias. Esta Sentencia considera justificado el acuerdo y entiende que la falta de reiteración en la política de retención de beneficios es un indicio en contra del abuso de derecho. La SAP de Murcia (Sección 4') de 28 de enero de 2005 UUR 2005, 62936) tampoco entiende en el caso enjuiciado que el acuerdo social de retención de beneficios para destinarlos para remanente constituya un abuso de derecho, puesto que la retención de beneficios no implica beneficios para unos socios y perjuicio para otros. Ni la Sentencia de la Audiencia Provincial de Valencia (Sección 9') de 13 de octubre de 2008 (AC 2008, 2073) que considera que el acuerdo de retención no es abusivo porque está justificado por razones económicas. En concreto, en el acta de la Junta se recogió como motivo de la retención la bajada de ventas en el ejercicio 2007 (un 20\% aproximadamente) y la necesidad de liquidez para el pago a proveedores.

Finalmente, también queremos citar la Sentencia de la Audiencia Provincial de Valencia (Sección Séptima) de 15 de septiembre de 1997 (AC 1997, 2268). En concreto, se declaró procedente la impugnación de un acuerdo social que imputó la totalidad de los beneficios obtenidos en el ejercicio 1994 a reservas voluntarias. La Sentencia estimó que existió abuso de derecho, fraude de ley y falta de buena fe. El abuso derivaba del no reparto de dividendos de forma reiterada y sistemática desde 1987. En cuanto al fraude de ley, la Sentencia considera que la Junta General se ampara en la norma del art. 213 LSA para 
Igualmente queremos resaltar, respecto de esta nueva causa de separación, que la misma se aplicaría a supuestos de mayoría ordinaria y no, como hasta ahora, de mayoría reforzada. Efectivamente, el fundamento básico del derecho de separación albergaba una protección excepcional del socio (minoritario) respecto de las decisiones tomadas por la mayoría para casos donde el cambio que éste debía aceptar era sin duda estructural: cambio/modificación del objeto social, transformación en otro tipo social, traslado internacional de domicilio, modificación del contenido de las prestaciones accesorias o modificación del régimen de transmisibilidad de las acciones $\mathrm{o}$ participaciones sociales, etc. Todas estas modificaciones a la estructura societaria tienen en común que la mayoría solicitada para aprobarlos debe ser, cuanto menos, reforzada. No ocurre lo mismo con el supuesto de separación por falta de reparto de dividendos. En este caso, la mayoría necesaria para aprobar las cuentas anuales y la consiguiente aplicación del resultado, es la mayoría ordinaria que, en unos casos, corresponderá a un tercio del capital social -sociedades de responsabilidad limitada-, mientras que en otros, puede no necesitar más aprobación que la mayoría simple de los socios asistentes a la junta general ordinaria, cuestión que, sin duda, contribuye a devaluar la importancia del principio mayoritario $\mathrm{y}$, pone de relieve, la necesidad de una urgente reforma legislativa $^{35}$.

En cuanto a los problemas relacionados con el límite cuantitativo del reparto de dividendos necesario para obviar la aplicación de esta causa de separación, sin duda, puede reconocerse la voluntad legislativa de evitar la aplicación fraudulenta del precepto, -consistente, sin duda, en el reparto de una cantidad testimonial-, estableciendo, para ello, una cifra proporcional concreta que excede seguramente de los límites de lo razonable, máxime si tenemos en cuenta que, la conceptualización del

vulnerar el artículo 48.2.a) LSA, actuando el artículo 213 LSA como norma de cobertura. La retención de beneficios destinados a reservas voluntarias perseguía el objetivo final de no proceder a la distribución de dividendos entre los socios.

Vid, BRENES CORTES, J. “El derecho de separación, principales novedades...” , op. cit., p. 33; CAMPINS VARGAS, A. "Derecho de separación por no reparto de dividendos...", op. cit. GONZÁLEZ CAST1LLA, F. "Reformas en materia de separación...", op. cit., p. 328; GONZÁLEZ CASTILLA, F. “Reformas en materia de separación...”, op. cit., p. 332.

${ }^{35}$ Tal sería el caso de las SA que aprobasen el no reparto de dividendos en segunda convocatoria. En primera convocatoria el requisito de quórum es algo mayor -25 por 100 del capital con derecho a voto- esto no obsta para señalar que a pesar de ello, no deja de ser una mayoría ordinaria. 
término "beneficios propios de la explotación" también presenta problemas en cuanto a su contenido. Creemos que los beneficios aludidos, abarcan los resultados económicos anteriores a la sustracción de los gastos financieros extraordinarios, de ejercicios anteriores y tributarios de los beneficios de la explotación .

Por otra parte, al determinarse la obligación de reparto de dividendos, no se establece si para la generación del derecho a separarse, el socio habrá de haberse manifestado en favor del reparto de dividendos en cada uno de los ejercicios anteriores o solamente en el último. Al respecto, también hay que tener en cuenta la práctica generalizada (sobre todo en pequeñas y medianas empresas) en orden a no celebrar en fecha la junta anual ordinaria, en cuyo caso, el socio no podría manifestar su desacuerdo con la falta de reparto de dividendos, mecanismo que dejaría vacío de contenido este elemento de "defensa de la minoría".

\subsection{La falta de distribución de dividendos en el Anteproyecto de Ley de Código Mercantil $^{36}$.}

En relación al régimen de la separación del socio, el Anteproyecto de Ley de Código Mercantil lo regula en el Título VII, "De la separación y de la exclusión de los socios, disolución, liquidación y extinción de las sociedades mercantiles", recogiendo por una parte, la separación de los socios, que de manera general atribuirá al socio el derecho de

\footnotetext{
${ }^{36}$ El pasado 30 de mayo de 2014 el Consejo de Ministros aprobó el Anteproyecto de Ley del Código Mercantil. Esta importantísima norma inició su andadura en noviembre de 2006, cuando el Ministro de Justicia encargó a la Sección Segunda, de Derecho Mercantil, de la Comisión General de Codificación la elaboración de un nuevo Código Mercantil. El Anteproyecto de Ley presenta significativas diferencias con la Propuesta de Código elaborado por la Comisión de Codificación y presentado el 17 de junio de 2013, texto de sólida base académica en el que participaron durante casi trece años un numeroso grupo de reconocidos juristas y que ha sido la base del Anteproyecto pero que, tras el período de información pública, en el que se han presentado numerosísimas alegaciones por parte de diversos sectores económicos, colectivos profesionales, despachos de abogados, etc, y tras la «negociación» del mismo con los órganos políticos (los Ministerios de Justicia y de Economía y Competitividad), ha sufrido modificaciones. El texto resultante que ha sido aprobado es el siguiente: 1.726 artículos divididos en un título preliminar y siete libros. Ahora, tras los preceptivos informes del Consejo General del Poder Judicial, el Consejo Fiscal, la Comisión Nacional de los Mercados y la Competencia y el Consejo de Estado, entrará en el Congreso para su tramitación como Proyecto de Ley, previsiblemente en octubre de este año 2014. Si se cumple el calendario previsto la Ley estará aprobada para el verano de 2015, aunque su entrada en vigor será paulatina y con una vacatio inicialmente prevista de tres meses, que será prorrogada con gran probabilidad, dado el alcance de la norma y la necesidad de un plazo suficiente de adaptación a la misma por todos los sujetos afectados, que son muchos
} 
separación por justa causa, seguida de un listado común de supuestos, en el que la separación se apoya en la discrepancia del socio respecto de los acuerdos que alteran sensiblemente el estatus quo societario, pasando de este marco general, a otro específico para las sociedades de personas y para las sociedades de capital.

Como es lógico, este marco general se diversifica luego en listados de causas específicas para las sociedades de personas y para las sociedades de capital, -excluidas las sociedades cotizadas-, y se complementa con la mención de causas particulares en la sociedad limitada, relacionadas con la transmisión de participaciones, además de con la previsión de ampliación de causas vía estatutaria, sin necesidad de consentimiento unánime de los socios una vez que el hecho de incorporar, modificar o suprimir causas de separación es, en sí mismo, causa de separación.

En este contexto, se ha considerado oportuno mantener el derecho de separación que trae causa en la falta de reparto de beneficios en las sociedades de capital, si bien se han restringido las circunstancias de cuantía y tiempo que habilitan el derecho con el fin de establecer un mayor equilibrio entre el legítimo interés de la sociedad a aplicar razonablemente el resultado y el del socio a hacer efectiva su participación en el beneficio repartible, evitando a la vez los eventuales abusos de mayoría que se concretan en reiteradas estrategias de neutralización del derecho económico de los socios en minoría.

Si el suspendido art. 348 bis LSC regula el derecho de separación por falta de reparto de dividendos, empezando a contar a partir del quinto ejercicio desde la inscripción en el RM de la sociedad y para poder ejercer este derecho es necesario que quien alega este artículo hubiese votado a favor de repartir dividendos y que la junta general hubiera acordado no repartirlos o repartir menos de un tercio de los beneficios propios de la explotación del objeto social obtenidos durante el ejercicio anterior, teniendo que ser estos beneficios legalmente repartibles. Por lo tanto, es importante remarcar que el beneficio a tener en cuenta es el de la explotación ordinaria, sin tener en cuenta beneficios atípicos/extraordinarios. (Para ejercer este derecho el socio tiene un plazo de un mes desde la celebración de la junta general ordinaria).

Pues bien, la novedad del Anteproyecto de Ley de Código Mercantil consiste en :

El art. 271-6 de la propuesta también reconoce el derecho a partir del quinto ejercicio y sobre los beneficios de la explotación del objeto social, pero se reduce el dividendo 
mínimo de un tercio a un cuarto. Además, se declara que los beneficios deben provenir de los dos últimos ejercicios.

La primicia que se propone en la regulación de este derecho de separación se halla en el art. 271-6.2 que dice: "El derecho de separación no podrá ejercitarse si existiese un acuerdo de refinanciación homologado por el juez, o si la sociedad se encuentra en concurso”. De este modo se protege la refinanciación de las empresas, pues el actual art. 348 bis LSC es un precepto que puede frenar a los acreedores e inversores.

\section{REFLEXIONES FINALES}

Aunque es una realidad que en nuestros días no existen criterios doctrinales unitarios en relación al fundamento del derecho de separación, la tendencia legislativa ha experimentado un cierto fortalecimiento, fomentándose una mayor cultura del derecho de salida, como ejemplo de ello es el aumento de causas legales y la inclusión del nuevo artículo 348 bis en la LSC que facilita la salida de los socios en caso de falta de distribución de dividendos.

Por otra parte, tanto la Dirección General de los Registros y del Notariado como el Tribunal Supremo, admiten el derecho de salida libre y voluntario del socio o separación sin causa o "ad nútum”, basándose en una interpretación abierta del artículo 96 LSRL (Actual 347 TRLSC) en sentencias como STS de 14 de marzo de 2013 y STS de 11 de noviembre de 2011, que admiten la separación ad nútum siempre que se cumplan los requisitos exigidos para su ejercicio.

No obstante, a propósito de la jurisprudencia más reciente, queremos poner en valor los posibles efectos adversos que el ejercicio del derecho de separación podría acarrear al patrimonio del tejido empresarial en los momentos de inflexión que vive nuestra economía social (SAP de Zaragoza en la Sentencia de 24 de enero de 2012 que da la razón al socio y obliga a la sociedad a abonarle el valor de su participación y los otros dos socios ejercieron abusivamente -en fraude de ley- su derecho a separarse. Y, en el mismo sentido, la STS de fecha 14 de abril de 2014 que resuelve sobre el criterio para valorar las participaciones de un socio separado en un caso en que, a consecuencia de la separación, la sociedad incurre en causa de disolución). 
En relación al polémico art. 348 bis TRLSC, suspendido hasta 31/12/2016, es de destacar la tendencia que sigue manteniéndose en el Anteproyecto de Ley de Código Mercantil, con algunas modificaciones de cuantía y tiempo, lo que lleva a hacernos pensar que el legislador pretende mantener este instrumento de protección de la minoría desfavorecida conciliando de mejor manera los enfrentados intereses entre la compañía y el minoritario. En esta ocasión, el Anteproyecto de Ley incluye un importante límite: "el no poder ejercitarse el derecho al dividendo, si existiese un acuerdo de refinanciación homologado por el juez o si la sociedad se encuentra en concurso", lo que nos conduce a reflexionar que, el legislador, dentro del difícil equilibrio que tiene que proteger optará, como primera prioridad, por la refinanciación de la compañía -apostando por su urgente recuperación, como verdadero motor económico y de creación de empleo que es, esencialmente, por la pequeña y mediana empresa-.

En el mismo sentido, y para evitar posibles efectos indeseados, desde el pasado 24 de diciembre, a través de la Ley $31 / 2014$ de 3 de diciembre, se vuelve a modificar la Ley de Sociedades de Capital para la Mejora del Gobierno Corporativo, reforma encaminada a evitar situaciones como las vividas actualmente en el seno de muchas sociedades cotizadas y con el fin de aumentar la confianza en accionistas e inversores. Para ello, se proponen medidas de modernización y mejora del Gobierno Corporativo de las sociedades de capital, contemplando, modificaciones en relación a temas tan importantes como la transparencia en los órganos de gobierno, que el accionista pueda tener mayor control de la gestión o los diversos deberes de los administradores, como el de diligencia o lealtad, intentando así evitar posibles conflictos entre socios.

Concluyendo, a fecha de hoy, las posibilidades que tiene un socio para abandonar la empresa y recuperar su inversión cuando es "víctima de opresión" por comportamientos abusivos, desleales o extrasociales son más teóricas que reales, pues la práctica nos demuestra que las opciones existentes son muy limitadas e improbables, fuera de las causas legales o estatutarias-, si tenemos en cuenta que, además de las reglas de transmisión de acciones/participaciones, que ya de hecho dificultan el proceso, encontrar un comprador que pague un precio razonable, resulta casi imposible. Por ello, de momento, la única posibilidad de evitar una vinculación indefinida entre los socios minoritarios y la sociedad es prever pactar en los estatutos 
sociales determinadas causas de salida distintas a las legales o intentar acudir a los tribunales y alegar justa causa o el abuso del derecho. 